\title{
The association of problematic eating behaviours with food quality and body mass index at 7 years of age
}

\author{
Sara Costa ${ }^{1} \cdot$ Andreia Pinto $^{1} \cdot$ Ana Cristina Santos ${ }^{1,2} \cdot$ Andreia Oliveira $^{1,2}$
}

Received: 11 September 2017 / Revised: 27 March 2018 / Accepted: 29 March 2018

(c) Macmillan Publishers Limited, part of Springer Nature 2018

\begin{abstract}
Background/objectives There is scarce evidence of how certain eating behaviours compromise the compliance with dietary guidelines and weight status in school-aged children. This study aims to evaluate the association of children's problematic eating behaviours with food quality and body mass index at 7 years of age.

Subjects/methods Participants were children aged 7 years old from a population-based cohort study from Porto, PortugalGeneration XXI. Children's quantity and speed of ingestion, food refusal at the table and food rewards requesting were evaluated by caregiver's perception. Food consumption was evaluated by a food frequency questionnaire and compared with age-appropriate guidelines. Children's weight status was assessed by objective measurements and parent's perceptions. Associations were estimated by logistic regressions (odds ratio (OR), 95\% confidence intervals (95\% CI)) adjusted for maternal age, education, smoking during pregnancy, birth type, child's sex, weight-for-gestational age and sports $(n=$ 3801).

Results Children eating small amounts of food, refusing to eat at the table with the rest of the family during meals and asking for food rewards showed a higher consumption of energy-dense foods $(\mathrm{OR}=1.51 ; 95 \% \mathrm{CI}: 1.23-1.86$; OR $=1.58 ; 95 \%$ CI:1.16-2.16; OR $=1.56 ; 95 \% \mathrm{CI}: 1.14-2.12)$ and presented higher odds of consuming fruit and vegetables below recommendations $(\mathrm{OR}=1.41 ; 95 \% \mathrm{CI}: 1.22-1.64 ; \mathrm{OR}=1.20 ; 95 \% \mathrm{CI}: 1.00-1.45$; OR $=1.28 ; 95 \% \mathrm{CI}: 1.05-1.55)$. Children displaying these eating behaviours were less likely to be overweight/obese, hence their parents were less likely to show concern with their weight. Including food quality as covariate in the final models with obesity status did not change the associations.

Conclusions Problematic eating behaviours were associated with poorer food quality (more energy-dense foods and low fruit and vegetables), but food quality does not seem to explain the association with obesity status. Parents were less likely to be concerned about their child's weight if the child ate slowly or poorly, and accordingly the odds of them being overweight or obese were lower.
\end{abstract}

\section{Introduction}

Eating behaviours are established during early childhood, and as children grow, some deviations from the expected eating behaviours may be perceived by caregivers $[1,2]$.

Andreia Oliveira

acmatos@ispup.up.pt

1 EPIUnit-Institute of Public Health, University of Porto, Porto, Portugal

2 Department of Public Health and Forensic Sciences, and Medical Education, Unit of Epidemiology, Faculty of Medicine, University of Porto, Porto, Portugal
Despite variation on the definition of problematic eating behaviours, these include food refusal (of certain types of foods), food fussiness or pickiness (refusal of new and familiar foods, accepting only a narrow range of foods), refusal of new foods (neophobia), grumpiness during mealtime and inadequate self-feeding skills [1, 3, 4]. The prevalence of these eating behaviours may vary between 7 and $65 \%[4,5]$.

It has been reported that diets of picky eaters may lack variety $[6,7]$ and quantity $[1,5,8-12]$, since the most refused groups are vegetables [5, 8-17] and fruits [16, 18], because of less palatable tastes, which, according to a longitudinal study, may result in a low energy intake [8]. A longitudinal study has described a higher consumption of sweetened foods among pickier children [16] and such has 
also been reported among fussier children in cross-sectional analysis [12]. In a longitudinal study, it was reported that fruit and vegetable consumption was associated with a higher child's enjoyment of food, but negatively related with slowness in eating, food refusal and satiety responsiveness [15]. Nevertheless, total energetic intake of children displaying these behaviours is not always low, as these children tend to compensate with preferred items, namely energy-dense foods [14]. In fact, according to a crosssectional study, children's food preferences usually do not comply with dietary recommendations [19].

Eating behaviours seem to have an effect in children weight status as well.

In school-aged children, Satiety Responsiveness/Slowness in Eating and Food Fussiness were negatively associated with weight, while Food Responsiveness, Enjoyment of Food, Emotional Overeating and Desire to Drink were positively associated [20] in a cross-sectional study. Fussy or picky eating behaviours have been associated with child's body weight in both cross-sectional [21] and longitudinal analyses $[10,14]$. According to a crosssectional study, parents may have misconceptions about their children's weight [22]. Parents of pre-schoolers showed concern about their children becoming overweight and such concern was prospectively related to parental child-feeding practices $[23,24]$ that may compromise dietary intake.

To the best of our knowledge, research so far has been largely focused on parental child-feeding practices (overt vs. covert control) or the family food environment, such as exposure or modelling [25, 26]. There has been evidence that children's problematic eating behaviours compromise the attainment of guideline recommendations for schoolaged children, and may equally affect their body weight, but such evidence is scarce.

This study aims to evaluate the association of children's problematic eating behaviours, perceived by their caregivers, with their food quality and body mass index (BMI) at 7 years of age. We also aimed to examine whether food quality could explain part of the association between problematic eating behaviours and BMI status.

The authors puts into hypothesis that problematic eating behaviours assessed in the present study would be related with poor diet quality and the relation with actual child's weight would depend on their profile of "food avoidance" (such as eat small amounts, slowly, food refusal) or "food approach" (such as eat large amounts of food) behaviours. Parental concerns with child's weight and actual weight would be higher among those parents with "food approach" behaviours. The relation between problematic eating behaviours and BMI may be partly explained by children's food quality.

\section{Methods}

\section{Participants}

Participants are children from Generation XXI (G21), a prospective population-based birth cohort, described elsewhere [27]. Women were recruited from all public maternity units from Porto, Portugal, between April 2005 and August 2006. A total of 8647 new-borns and 8495 mothers were enroled at baseline. Of the invited mothers, $91.4 \%$ agreed to participate [8]. At 4 years of age, a follow-up evaluation took place between April 2009 and August 2011 and 7459 children were evaluated ( $86 \%$ participation rate). At the third follow-up evaluation (7 years old), 6889 children were evaluated between April 2012 and March 2014.

A cross-sectional analysis was conducted with data from the 7-year-old wave. Twins and participants, who had no information for dietary intake, weight and height and the main variables of interest, were excluded. Overall, it includes 3801 children with complete data for the variables of interest. We compared the study sample $(n=3801)$ characteristics with the remaining cohort $(n=4846)$ at baseline, and no significant differences were found for child's sex (51.5 vs. $50.7 \%$ of boys, $p=0.460)$. However, mothers included in this study were slightly older (mean $=$ 29.9; $\mathrm{SD}=5.10$ vs. mean $=28.2 ; \mathrm{SD}=5.85 ; p<0.001$ ) and more educated $($ mean $=11.4 ; \mathrm{SD}=4.28$ vs. mean $=$ 9.7; $\mathrm{SD}=4.09 ; p<0.001)$ than mothers in the remaining cohort. However, the Cohen's effect size values were lower than 0.40 , suggesting that the magnitude of the differences was not high (i.e., differences were at most part due to the large sample size than due to large differences between participant's characteristics) [28].

All the phases of the study complied with the Ethical Principles for Medical Research Involving Human Subjects expressed in the Declaration of Helsinki (World Medical Association, 2013). The study was approved by the University of Porto Medical School/S. João Hospital Centre ethics committee and a signed informed consent according to the Declaration of Helsinki was required for all participants.

\section{Data collection}

Information on maternal and children characteristics were collected by face-to-face interviews performed by trained researchers, using structured questionnaires or retrieved from medical records.

At baseline, maternal age and education, smoking habits during pregnancy, type of delivery, child's sex, birth weight and gestational age were available. Weight-for-gestational age was defined according to sex-specific population-based Kramer growth standards [29]. Any breastfeeding duration 
Table 1 Prevalence of 7-year-old children's problematic eating behaviours perceived by the mother

\begin{tabular}{lc}
\hline & $\mathrm{n}=3801$ \\
\hline Eat small amounts of food, $n(\%)$ & $2127(56.0)$ \\
No & $1674(44.0)$ \\
Yes & \\
Eat large amounts of food, $n(\%)$ & $3040(80.0)$ \\
No & $761(20.0)$ \\
Yes & $1804(47.5)$ \\
Eat very slowly, $n(\%)$ & $1997(52.5)$ \\
No & $3222(84.8)$ \\
Yes & $579(15.2)$ \\
Refusal to eat at the table with the rest of the family, $n(\%)$ \\
No & $3240(85.2)$ \\
Yes & $561(14.8)$ \\
Demand for food rewards, $n(\%)$ & \\
No & \\
Yes &
\end{tabular}

(at 4 years of age) and family structure and sports practice (at 7 years of age) were asked about.

At 7 years of age, children's eating behaviours were reported according to the perception of the main caregiver (94\% were mothers), using questions concerning: quantity (eating small amounts and large amounts of food) and speed of food intake, refusal to eat at the table with the rest of the family and request for reward-type foods (energy-dense foods) (Table 1). Some of these questions, such as "eat small amounts of food", "eat very slowly" and "eat large amounts of food", were derived from subscales of the Children's Eating Behaviour Questionnaire (CEBQ) [30].

The original CEBQ has demonstrated stability over time and good psychometric properties in several populations all over the world [30-33], including the Generation XXI sample at 7 years of age [34]. When testing the correlations between the questions "eat small amounts of food", "eat very slowly" and "eat large amounts of food" with the corresponding sub-domains in the original CEBQ, i.e., Food Fussiness, Slowness in Eating and Food responsiveness, the point-biserial correlations were moderate to high: rho $=0.300(p<0.001)$, rho $=0.632(p<0.001)$ and rho $=0.523(p<0.001)$, respectively, for the three questions referred.

Dietary intake was assessed by a 38-item food frequency questionnaire (FFQ) covering the previous 6 months. Response frequency options varied between "more than 4 times per day" and "never". Dietary intake was categorised into below, according to or above dietary guidelines for all food groups except for energy-dense foods, which only had two categories (according to and above guidelines). The dietary guidelines used in this study were recommendation intervals for children of this age using an average of three countries, assessed in a previous study [35]. To assess the validity of the FFQ, 3-day food records were also completed by the main caregiver(s) of a sub-sample of 3511 children, and the dietary intake obtained from both methods were compared using intra-class correlation coefficients (ICCs) and de-attenuated Pearson's correlation coefficients. The highest ICC was obtained for "vegetable soup" (ICC = 0.430). Significant correlation coefficients were observed for all nutrients; the average of correlation coefficients was 0.42 . We also compared the FFQ results with serum biomarkers in a sub-sample of 80 children at 7 years of age. The de-attenuated correlation coefficients were: $r=0.282$ $(p=0.120)$ for plasma concentration of vitamin A and $r=$ $0.425(p=0.027)$ for folate.

Weight and height were objectively measured by trained researchers in accordance with standardised procedures [36]. The BMI was calculated as the weight over the squared height $\left(\mathrm{kg} / \mathrm{m}^{2}\right)$. Each child was then classified according to the age- and sex-specific BMI reference $z$ scores developed by the World Health Organization [37], and recoded into underweight or normal weight (BMI $<2$ SD) and overweight/obese (BMI $>2 \mathrm{SD}$ ).

In addition, caregiver's perception of their child weight was assessed by four questions of the Child Feeding Questionnaire (Table 2), previously validated in this cohort [38].

\section{Statistical analysis}

To assess the associations between eating behaviours and food quality, a multinomial logistic regression model was computed, using as reference category children with diet according to guidelines. Different models were run for each eating behaviour, since there were moderate correlations between some of them. Odds ratios (ORs) and the respective $95 \%$ confidence intervals $(95 \% \mathrm{CIs})$ were calculated, after adjustment for maternal age and education, smoking during pregnancy, breastfeeding duration, child's sex, living with siblings and child BMI $z$-score at 7 years of age.

To assess the associations between eating behaviours and categories of child's BMI $z$-score and mother's concerns about child's weight, a binary logistic regression model was computed, after adjustment for maternal age and education, smoking during pregnancy, type of birth, child's sex, birth weight for gestational age and child's sports practice.

The selection of confounders in each model was based on a previous literature search to identify a set of potential confounders, and then they were included in each model, based on a stepwise method, to see if they are actual confounders of each association under study. Those that changed the study associations (change of at least $10 \%$ in the odds ratios) were kept into models, as co-variables; they 
Table 2 Prevalence of mother's perception and concerns about child's weight at 7 years of age

\begin{tabular}{lr}
\hline & $n=3801$ \\
\hline $\begin{array}{l}\text { Mother's perception of her child's weight, } n(\%) \\
\text { normal weight }\end{array}$ & $3359(88.4)$ \\
Overweight or & $442(11.6)$ \\
obese & \\
Mother is concerned that her child overeats when she is absent, $n(\%)$ \\
No & $2721(71.6)$ \\
Yes & $1080(28.4)$ \\
Mother is concerned that a diet will be required for her child, $n(\%)$ \\
No & $2512(80.0)$ \\
Yes & $1289(33.9)$ \\
Mother is concerned that her child becomes overweight & or obese, $n$ \\
$(\%)$ & $1708(44.9)$ \\
No & $2093(55.1)$ \\
Yes &
\end{tabular}

were different according to the outcome under study: food quality and weight status.

To test whether food quality explained part of the association between eating behaviours and BMI, we included the different "food quality" variables in the final models having as outcome the obesity status and as exposure the different problematic eating behaviours.

A significance level of 5\% was considered in all analyses, performed using IBM SPSS (Statistical Package for Social Sciences) Statistics 24.0 ${ }^{\mathrm{TM}}$ (SPSS Inc., Chicago, IL, USA).

\section{Results}

This study includes 3801 children, $48.5 \%$ were girls and one-quarter were overweight or obese at 7 years of age (26.1\%) (Table 3).

The prevalence of children's problematic eating behaviours is presented in Table 1. According to mother's perception, the eating behaviours more frequently reported were "eat very slowly" (53.0\%) and "eat small amounts of food" $(45.0 \%)$ (Table 1). More than $50.0 \%$ (55.1\%) reported concerns that her child would become overweight or obese (Table 2).

Table 4 shows the prevalence of children's dietary intake according to guidelines, specific for this age group. Only $57.0 \%$ followed the guidelines for fruit and vegetables, similar to dairy products $(47.0 \%)$. The majority of children (87.0\%) consumed energy-dense foods 6 or more times per week (above guidelines).
Table 3 Mother and child's characteristics

\begin{tabular}{|c|c|}
\hline & $n=3801$ \\
\hline $\begin{array}{l}\text { Maternal age } \\
\text { mean (SD) }\end{array}$ & $29.9(5.10)$ \\
\hline $\begin{array}{l}\text { Maternal } \\
\text { education mean } \\
\text { (SD) }\end{array}$ & $11.4(4.28)$ \\
\hline \multicolumn{2}{|c|}{ Smoking during pregnancy, $n(\%)$} \\
\hline No & $3089(81.3)$ \\
\hline Yes & $712(18.7)$ \\
\hline \multicolumn{2}{|c|}{ Type of birth, $n(\%)$} \\
\hline Vaginal & $2354(61.9)$ \\
\hline C-section & $1447(38.1)$ \\
\hline \multicolumn{2}{|c|}{ Child's sex, $n(\%)$} \\
\hline Boys & $1956(51.5)$ \\
\hline Girls & $1845(48.5)$ \\
\hline \multicolumn{2}{|c|}{ Birth weight-for-gestational age ${ }^{\mathrm{a}}, n(\%)$} \\
\hline $\begin{array}{l}\text { Small-for- } \\
\text { gestational age }\end{array}$ & $531(14)$ \\
\hline $\begin{array}{l}\text { Appropriate for } \\
\text { gestational age }\end{array}$ & $3124(82.2)$ \\
\hline $\begin{array}{l}\text { Large-for- } \\
\text { gestational age }\end{array}$ & $146(3.8)$ \\
\hline \multicolumn{2}{|c|}{ Breastfeeding duration, $n(\%)$} \\
\hline Never & $240(6.3)$ \\
\hline$<3$ Months & $781(20.5)$ \\
\hline 3-6 Months & $660(17.4)$ \\
\hline$>6$ Months & $2120(55.8)$ \\
\hline \multicolumn{2}{|c|}{ Living with siblings, $n(\%)$} \\
\hline No & $1467(38.6)$ \\
\hline Yes & $2334(61.4)$ \\
\hline \multicolumn{2}{|c|}{ Child's $z$-score $\mathrm{BMI}^{\mathrm{b}}, n(\%)$} \\
\hline $\begin{array}{l}\text { Underweight or } \\
\text { normal weight }\end{array}$ & $2810(73.9)$ \\
\hline $\begin{array}{l}\text { Overweight or } \\
\text { obese }\end{array}$ & $991(26.1)$ \\
\hline \multicolumn{2}{|c|}{ Sports practice, $n(\%)$} \\
\hline No & $556(14.6)$ \\
\hline Yes & $3245(85.4)$ \\
\hline
\end{tabular}

BMI body mass index

a Weight for gestational age defined according to the sex-specific population-based Kramer growth standards (cut-points: 10th and 90th percentile) [25]

${ }^{b}$ Child's BMI was classified according to the age- and sex-specific BMI standard $z$-scores developed by the World Health Organization [29]

Table 5 presents the results of the multivariate associations between children's eating behaviours and food quality. According to mother's perception, children who eat small amounts of food had significantly higher odds of consuming fruit and vegetables $(\mathrm{OR}=1.41 ; 95 \% \mathrm{CI}: 1.22-1.64)$ and 
Table 4 Prevalence of 7-year-old children's adequacy of intake according to guidelines ${ }^{\mathrm{a}}$

\begin{tabular}{|c|c|c|}
\hline & Guidelines cut offs ${ }^{\mathrm{a}}$ & $n=3801$ \\
\hline \multicolumn{3}{|l|}{ Meat and eggs ${ }^{\mathrm{b}}, n(\%)$} \\
\hline Below guidelines & $<5$ Times/week & $491(12.9)$ \\
\hline According to guidelines & 6-10 Times/week & $3061(80.5)$ \\
\hline Above guidelines & $>10$ Times/week & $249(6.6)$ \\
\hline \multicolumn{3}{|l|}{ Seafood $^{\mathrm{c}}, n(\%)$} \\
\hline Below guidelines & $<2$ Times/week & $246(6.5)$ \\
\hline According to guidelines & 2-4 Times/week & $1641(43.2)$ \\
\hline Above guidelines & $>4$ Times/week & $1914(50.4)$ \\
\hline \multicolumn{3}{|l|}{ Dairy $^{\mathrm{d}}, n(\%)$} \\
\hline Below guidelines & $<3$ Times/day & $986(25.9)$ \\
\hline According to guidelines & 3-5 Times/day & $1802(47.4)$ \\
\hline Above guidelines & >5 Times/day & $1013(26.7)$ \\
\hline \multicolumn{3}{|l|}{ Fruit and vegetables ${ }^{\mathrm{e}}, n(\%)$} \\
\hline Below guidelines & $<4$ Times/day & $1357(35.7)$ \\
\hline According to guidelines & 4-7 Times/day & $2161(56.9)$ \\
\hline Above guidelines & >7 Times/day & $283(7.4)$ \\
\hline \multicolumn{3}{|l|}{ Energy-dense foods ${ }^{\mathrm{f}}, n(\%)$} \\
\hline According to guidelines & $<6$ Times/week & $494(13.0)$ \\
\hline Above guidelines & $\geq 6$ Times/week & 3307 (87.0) \\
\hline
\end{tabular}

${ }^{a}$ The dietary guidelines are recommendation intervals for school-age children using an average of three countries, assessed in a previous study [27]

${ }^{\mathrm{b}}$ Meat and eggs (all types of white and red meats and eggs)

${ }^{\mathrm{c}}$ Sea food (all types of fish and shellfish)

${ }^{\mathrm{d}}$ Dairy (milk, chocolate milk, yogurts, cheese)

${ }^{\mathrm{e}}$ Fruit and vegetables (cooked or raw vegetables, all types of fruit, fruit juices and vegetable soup)

${ }^{\mathrm{f}}$ Energy-dense foods (pizza, burgers, crisps, sweet and salted pastry, cakes, snacks, candies, chocolate and sugar-sweetened beverages)

seafood below recommendations $(\mathrm{OR}=1.37,95 \% \mathrm{CI}$ : 1.03-1.82), i.e., consume less of those food groups, but consume more energy-dense foods (above vs. within recommendations: $\mathrm{OR}=1.51$; 95\% CI: $1.23-1.86)$. Children who eat very slowly had higher intake of meat and eggs (above vs. within recommendations: $\mathrm{OR}=1.50 ; 95 \%$ CI: 1.13-1.98), but lower of fruit and vegetables (above vs. within recommendations: $\mathrm{OR}=0.71$; 95\% CI: 0.55-0.92), as well as seafood (OR $=0.84,95 \%$ CI: $0.73-0.97)$. Furthermore, children who ask for food rewards were more likely to eat dairy products, meat and eggs and energydense foods above recommendations, but had lower intake of fruit and vegetables (below vs. within recommendations: $\mathrm{OR}=1.28$; 95\% CI: 1.05-1.55). On the other hand, children who refuse to eat at the table during meals had higher odds of energy-dense foods consumption above recommendation $(\mathrm{OR}=1.58 ; 95 \% \mathrm{CI}: 1.16-2.16)$, but lower odds of eating fruit and vegetables $(\mathrm{OR}=0.54 ; 95 \% \mathrm{CI}$ :

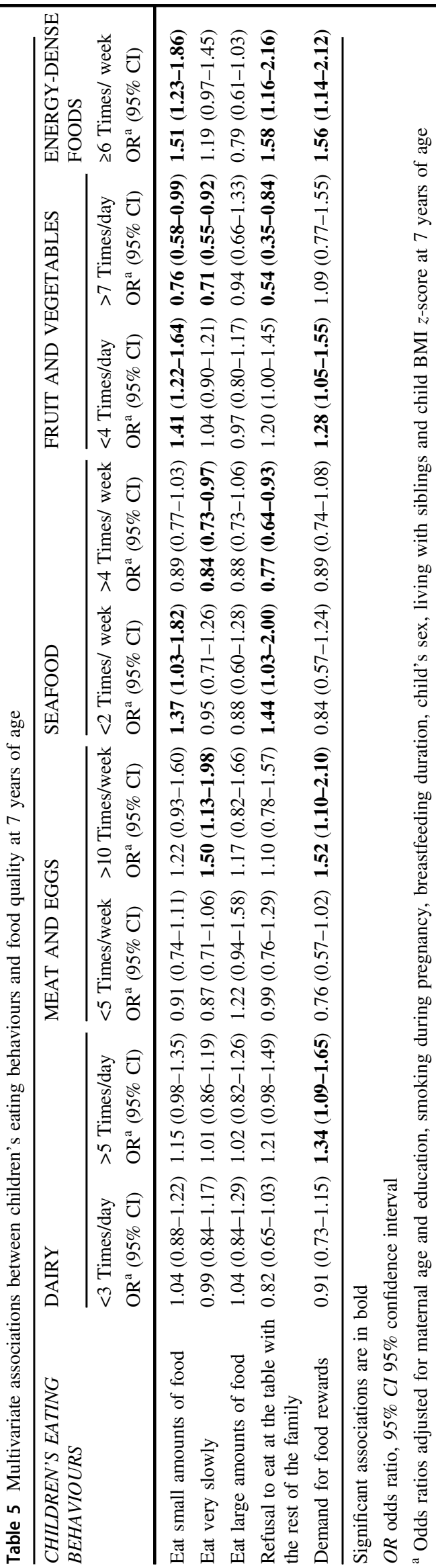


Table 6 Multivariate associations between children's eating behaviours and children's overweight/obesity and mother's concerns about her child's weight at 7 years of age

\begin{tabular}{|c|c|c|c|c|c|}
\hline \multirow[b]{3}{*}{$\begin{array}{l}\text { Children's eating } \\
\text { behaviours }\end{array}$} & \multirow{2}{*}{$\begin{array}{l}\text { Children's BMI } \\
\text { Normal weight vs. } \\
\text { overweight/obese }\end{array}$} & \multirow{2}{*}{$\begin{array}{l}\text { Mother's perception of } \\
\text { child's weight } \\
\text { High/very high vs. low }\end{array}$} & \multicolumn{3}{|c|}{ Mother is concerned that the child: } \\
\hline & & & $\begin{array}{l}\text { Overeats when she } \\
\text { is absent }\end{array}$ & $\begin{array}{l}\text { Will be required a } \\
\text { diet }\end{array}$ & $\begin{array}{l}\text { Becomes overweight } \\
\text { or obese }\end{array}$ \\
\hline & & $\mathrm{OR}^{\mathrm{a}}(95 \% \mathrm{CI})$ & $\mathrm{OR}^{\mathrm{a}}(95 \% \mathrm{CI})$ & $\mathrm{OR}^{\mathrm{a}}(95 \% \mathrm{CI})$ & $\mathrm{OR}^{\mathrm{a}}(95 \% \mathrm{CI})$ \\
\hline Eat small amounts of food & $0.22(0.19-0.26)$ & $0.18(0.14-0.24)$ & $0.48(0.41-0.55)$ & $0.56(0.49-0.64)$ & $0.58(0.51-0.66)$ \\
\hline Eat very slowly & $0.25(0.21-0.30)$ & $0.19(0.15-0.24)$ & $0.46(0.40-0.54)$ & $0.56(0.49-0.64)$ & $0.59(0.52-0.67)$ \\
\hline Eat large amounts of food & $8.47(7.10-10.12)$ & $14.6(11.5-18.2)$ & $4.20(3.54-4.98)$ & $3.67(3.10-4.34)$ & $3.30(2.74-3.96)$ \\
\hline $\begin{array}{l}\text { Refusal to eat at the table } \\
\text { with the rest of the family }\end{array}$ & $0.73(0.59-0.91)$ & $0.51(0.37-0.72)$ & $0.86(0.70-1.05)$ & $0.97(0.80-1.17)$ & $1.01(0.85-1.22)$ \\
\hline Demand for food rewards & $0.70(0.56-0.87)$ & $0.70(0.52-0.96)$ & $0.92(0.75-1.12)$ & $0.97(0.80-1.18)$ & $0.96(0.80-1.15)$ \\
\hline
\end{tabular}

Significant associations are in bold

OR odds ratio, $95 \%$ CI 95\% confidence interval, BMI body mass index

${ }^{a}$ OR adjusted for maternal age and education, smoking during pregnancy, type of birth, child's sex, weight for gestational age and child's sports practice

$0.35-0.84)$ and seafood above recommendations $(\mathrm{OR}=$ 0.77; 95\% CI: 0.64-0.93).

Children presenting these eating behaviours were less likely to be overweight or obese, whereas the reverse was observed if they eat large amounts of food (Table 6). When including the "food quality" variables as covariate of these models, the associations remained unchanged. Mothers of children who eat large amounts of food had much higher odds of perceiving their child's weight as high or very high and the opposite occurred in mothers of children showing the other eating behaviours. Concerns about the child overeating when the mother is absent, being in need of a diet or becoming overweight were less likely in mothers of children who eat small amounts of food or eat very slowly but were more likely when the child eats large amounts of food.

\section{Discussion}

Different children's eating behaviours were shown to affect food quality. Children eating small amounts of food, asking for food rewards and refusing to eat at the table with the rest of the family during meals showed a poorer food quality, consuming more energy-dense foods and less fruit and vegetables. Nonetheless, food quality did not explain the association between problematic eating behaviours and children's obesity status.

In a longitudinal study, Mascola et al. [7] previously concluded that parents of picky eaters (those who reject food, resulting in an insufficient amount of food consumption, somewhat comparable to children eating small amounts of foods in our study) were more likely to state a limited variety of foods consumed by their children. Children with more eating difficulties, as reported by parents at different ages, were also less likely to have more than one serving a day of fruit intake when compared with children with no eating difficulties in three different birth cohorts [1]. However, even with these problematic behaviours, fruit and vegetable intake in the Portuguese children was higher when compared with other European cohorts, such as ALSPAC, UK, and EDEN, France [13]. Furthermore, Galloway et al. [10] also found that children eating small amounts were more likely to eat energy-dense foods above recommendation. Food responsiveness, usually associated with obesity risk, has been correlated with enjoyment of energy-dense foods $[15,39]$.

In the UK, Fildes et al. [15] concluded that eating slowly was negatively associated with liking both fruit and vegetables and protein foods. Our findings suggest that there seems to be a pattern of children who eat small amounts of food and ask for food rewards, linked to higher consumption of meat and eggs. This difference could be explained by parental concerns on child's diet. Caregivers perceive them as eating poorly, and they insist on them eating meat and eggs (possibly for their protein value) before the rest of the food on the plate.

In the present study, we found that children who eat very slowly had lower odds of eating fruit and vegetables above recommendations. Fildes et al. [15] concluded that eating slowly was negatively associated with liking these groups, and a positive association of fruit and vegetable liking with enjoyment of food and a negative association with food fussiness were observed.

Other eating behaviours such as refusing to eat at the table with the rest of the family was linked to an unhealthy 
eating pattern, thus reinforcing the importance of a structured mealtime, since it has been reported that children whose mothers not only ate with them but also ate the same food as them refused fewer foods and were easier to feed compared with children whose mothers did not [40].

As for energy-dense foods, children from our study had consumption above recommendation across all five eating behaviours. In a previous study, eating behaviours of children of similar ages (8-12 years of age) were assessed, as reported by their primary caretakers, namely their mothers, and children showing more fussy behaviours (reported to avoid foods in general, somewhat comparable with some of the problematic eating behaviours assessed in our study, namely eating slowly and small amounts) also showed a preference for fast-food in comparison with their peers, suggesting they might be at risk of being overweight [41]. However, our results only support this positive association with weight gain for those who "eat large amounts of food". In fact, in the present study we put into hypothesis that child's weight and parental concerns with child's weight would be higher among those with children with "food approach" behaviours, such as eat large amounts of food, which was corroborated by the present results.

Eating slowly, as well as satiety responsiveness, stated as a "food avoidance" appetitive trait, were also previously linked to lower obesity risk in children [20]. Similarly, our results showed that children who eat very slowly or small amounts of foods were less likely to be overweight or obese and, accordingly, their parents were less likely to show concern about their weight (not perceiving it as high). However, children who eat excessive amounts of food were more likely to be overweight or obese, and thus their parents were more likely to be concerned about their weight or eating behaviour.

Previous research has described that picky eaters or fussier children (somewhat comparable to those eating small amounts of food in our study) have a lower body mass index $[10,14,20,21]$, as reported in our study. In children participating in the Physical Exercise and Appetite in Children Study (PEACHES) or the Twins Early Development Study (TEDS) aged 7-9 years and 9-12 years, food fussiness showed a graded negative association with weight [20]. De Barse et al. [14] studied 4-year-old fussy eaters and also found that their problematic eating behaviour was linked to a lower BMI and a higher risk of becoming underweight and having lower fat free mass than non-fussy eaters over a 2-year period, revealing the need to careful monitoring growth [14]. In a study, involving Portuguese children aged 3-13 years, food avoidance subscales of the CEBQ (more related with picky eating and fussiness) was also negatively related with BMI $z$-scores [21]. Nevertheless, a study conducted in 6-7-year-old children has not found an association between picky behaviours and BMI [42], neither other study conducted from 2 to 11 years [7].

As for mother's concerns about her child's weight, our results showed an accurate perception of the child's weight by their caregivers. In literature, little is known about weight perception among parents of normal weight children. However, in a recent study maternal underestimation of weight status was common among both overweight and normal weight children and such was linked to an increased risk of a child being overweight [22]. Weight misconceptions seem to be common by parents of overweight children, as stated in a systematic review [43]. However, mothers of children with a lower BMI are more likely to show concern for undereating, pressuring their children to eat [44]. Misconceptions about child's weight status, either underestimating or overestimating, may misguide parents' health-related behaviour and impact their children weight status [22, 45], keeping children away from early detection, preventive actions or even treatment [45-47]. Nevertheless, a longitudinal Canadian study reported that mother's perception of their children's eating behaviours (13-22\% expressing behaviours such as stronger likes or dislikes of foods, threw tantrums when denied foods and need of special meals, etc.) was prospectively associated with a higher body weight, as well as less dietary adequacy (the children consumed a limited variety of foods) at 4-5 years of age [8]. A longitudinal study also stated that children whose parents perceived their weight status accurately had a higher BMI over time, suggesting that parents recognised their child's being overweight but were possibly not able or were unwilling to manage their child's weight adequately [48].

Previous research was mainly focused on parental childfeeding practices, while in this study we also explored children's eating behaviours. In addition, we used data from a population-based cohort of children of the same age with a wide range of eating behaviours, confounding factors and anthropometrics measured, enhancing the internal validity of our study. Some limitations must also be pointed out. Both children's eating behaviours and dietary intake were reported by their caregivers, and accurate parental assessment of both may be biased. Nonetheless, the validity of the FFQ was assessed, and showed to have modest correlations with 3-day food diaries. The CEBQ, from which some questions used were derived, has also demonstrated stability over time and good psychometric properties in several populations all over the world [30-33], including the Generation XXI sample at 7 years of age [34]. The questions used in the present study showed moderate-to-high correlations with the original sub-domains of the CEBQ, giving robustness to our questions. Nevertheless, the possibility of misreport cannot be discarded. 
The cross-sectional nature of this study is also regarded as a limitation as it did not allow us to establish the correct direction of these associations. Future longitudinal analysis is required to examine these relationships prospectively and to replicate these findings in more diverse groups.

\section{Conclusions}

A poor food quality (high consumption of energy-dense foods and low of fruit and vegetables) was associated with children's eating small amounts of food, asking for food rewards and refusing to eat at the table with the rest of the family during meals. Slowly eating children were also identified as having meat and eggs consumption above recommendations.

Children who eat small amounts of food and very slowly were less likely to be overweight or obese, and accordingly their parents were less likely to show concern about their weight (not perceiving it as high). However, children who eat excessive amounts of food were more likely to be overweight or obese, and thus their parents were more likely to be concerned about their weight or eating behaviour.

Despite these problematic eating behaviours have been significantly associated with both food quality and overweight/obesity status, food quality does not seem to explain the association between problematic eating behaviour and obesity status.

Interventions at an early stage are mandatory, since taste, eating habits and behaviours are defined in early childhood, and tend to prevail in adult age [49-51] while carrying a social, emotional and physiological impact [52]. Strategies such as repeated exposure to the taste of a certain food tends to increase its liking by the child [25]. As for BMI associations, in future research, it would be relevant to measure body fat mass composition, since some children with these problematic eating behaviours may have adequate BMI but high fat mass.

Acknowledgements We are indebted to all participants for providing the data used in the Generation XXI birth cohort, as well as to all members of the research team and its coordinators (Henrique Barros and Ana Cristina Santos). The authors acknowledge the support from the Epidemiology Research Unit (EPIUnit: UID-DTP/04750/2013).

Funding Generation XXI was funded by the Health Operational Programme-Saúde XXI, Community Support Framework III and the Regional Department of Ministry of Health. This study was supported through FEDER from the Operational Programme Factors of Competitiveness (COMPETE) and through national funding from the Foundation for Science and Technology (FCT; Portuguese Ministry of Education and Science) under the project PTDC/SAU-EPI/121532/ 2010 (FCOMP-01-0124-FEDER-021177) and through the Investigator Programme (IF/01350/2015-Andreia Oliveira and IF/01060/ 2015-Ana Cristina Santos). It also had support from the Calouste Gulbenkian Foundation.

\section{Compliance with ethical standards}

Conflict of interest The authors declare that they have no conflict of interest.

\section{References}

1. Oliveira A, Jones L, de Lauzon-Guillain B, Emmett P, Moreira P, Charles MA, et al. Early problematic eating behaviours are associated with lower fruit and vegetable intake and less dietary variety at 4-5 years of age. A prospective analysis of three European birth cohorts. Br J Nutr. 2015;114:763-71.

2. Aldridge VK, Dovey TM, Martin CI, Meyer C. Identifying clinically relevant feeding problems and disorders. J Child Health Care. 2010;14:261-70.

3. Dovey TMSP, Gibson EL, Halford JC. Food neophobia and 'picky/fussy' eating in children: a review. Appetite. 2008;50:181-93.

4. van Dijk M, Bruinsma E, Hauser MP. The relation between child feeding problems as measured by parental report and mealtime behavior observation: a pilot study. Appetite. 2016;99:262-67.

5. Jacobi C, Agras WS, Bryson S, Hammer LD. Behavioral validation, precursors, and concomitants of picky eating in childhood. J Am Acad Child Adolesc Psychiatry. 2003;42:76-84.

6. Birch LL, Fisher JO. Development of eating behaviors among children and adolescents. Pediatrics. 1998;101:539-49.

7. Mascola AJ, Bryson SW, Agras WS. Picky eating during childhood: a longitudinal study to age 11 years. Eat Behav. 2010;11:253-7.

8. Dubois L, Farmer AP, Girard M, Peterson K. Preschool children's eating behaviours are related to dietary adequacy and body weight. Eur J Clin Nutr. 2007;61:846-55.

9. Dovey TM, Staples PA, Gibson EL, Halford JCG. Food neophobia and 'picky/fussy' eating in children: a review. Appetite. 2008;50:181-93.

10. Galloway AT, Fiorito L, Lee Y, Birch LL. Parental pressure, dietary patterns, and weight status among girls who are "picky eaters". J Am Diet Assoc. 2005;105:541-8.

11. Galloway AT, Lee Y, Birch LL. Predictors and consequences of food neophobia and pickiness in young girls. J Am Diet Assoc. 2003;103:692-8.

12. Carruth BR, Ziegler PJ, Gordon A, Barr SI. Prevalence of picky eaters among infants and toddlers and their caregivers' decisions about offering a new food. J Am Diet Assoc. 2004;104:s57-64.

13. de Lauzon-Guillain B, Jones L, Oliveira A, Moschonis G, Betoko A, Lopes C, et al. The influence of early feeding practices on fruit and vegetable intake among preschool children in 4 European birth cohorts. Am J Clin Nutr. 2013;98:804-12.

14. de Barse LM, Tiemeier H, Leermakers ET, Voortman T, Jaddoe VW, Edelson LR, et al. Longitudinal association between preschool fussy eating and body composition at 6 years of age: the Generation R Study. Int J Behav Nutr Phys Act. 2015;12:153.

15. Fildes A, Mallan KM, Cooke L, van Jaarsveld CH, Llewellyn CH, Fisher A, et al. The relationship between appetite and food preferences in British and Australian children. Int J Behav Nutr Phys Act. 2015;12:116.

16. Taylor CM, Northstone K, Wernimont SM, Emmett PM. Macroand micronutrient intakes in picky eaters: a cause for concern? Am J Clin Nutr. 2016;104:1647-56.

17. van der Horst K, Deming DM, Lesniauskas R, Carr BT, Reidy KC. Picky eating: associations with child eating characteristics and food intake. Appetite. 2016;103:286-93.

18. Cooke LJ, Wardle J. Age and gender differences in children's food preferences. Br J Nutr. 2005;93:741-6. 
19. Russell CG, Worsley A. Do children's food preferences align with dietary recommendations? Public Health Nutr. 2007;10:1223-33.

20. Webber L, Hill C, Saxton J, Van Jaarsveld CH, Wardle J. Eating behaviour and weight in children. Int $\mathrm{J}$ Obes (Lond). 2009;33:21-8.

21. Viana V, Sinde S, Saxton JC. Children's Eating Behaviour Questionnaire: associations with BMI in Portuguese children. Br J Nutr. 2008;100:445-50.

22. Vallejo M, Cortes-Rodriguez BA, Colin-Ramirez E. Maternal underestimation of child's weight status and health behaviors as risk factors for overweight in children. J Pediatr Nurs. 2015;30: e29-33.

23. Rodgers RF, Paxton SJ, Massey R, Campbell KJ, Wertheim EH, Skouteris $\mathrm{H}$, et al. Maternal feeding practices predict weight gain and obesogenic eating behaviors in young children: a prospective study. Int J Behav Nutr Phys Act. 2013;10:24.

24. Gregory JE, Paxton SJ, Brozovic AM. Maternal feeding practices, child eating behaviour and body mass index in preschool-aged children: a prospective analysis. Int $\mathrm{J}$ Behav Nutr Phys Act. 2010;7:55.

25. Cooke L. The importance of exposure for healthy eating in childhood: a review. J Hum Nutr Diet. 2007;20:294-301.

26. Shloim N, Edelson LR, Martin N, Hetherington MM. Parenting styles, feeding styles, feeding practices, and weight status in 4-12 year-old children: a systematic review of the literature. Front Psychol. 2015;6:1849

27. Larsen PS, Kamper-Jorgensen M, Adamson A, Barros H, Bonde JP, Brescianini S, et al. Pregnancy and birth cohort resources in Europe: a large opportunity for aetiological child health research. Paediatr Perinat Epidemiol. 2013;27:393-414.

28. Husted JA, Cook RJ, Farewell VT, Gladman DD. Methods for assessing responsiveness: a critical review and recommendations. J Clin Epidemiol. 2000;53:459-68.

29. Kramer MS, Platt RW, Wen SW, Joseph KS, Allen A, Abrahamowicz M, et al. A new and improved population-based Canadian reference for birth weight for gestational age. Pediatrics. 2001;108:E35.

30. Wardle J, Guthrie CA, Sanderson S, Rapoport L. Development of the Children's Eating Behaviour Questionnaire. J Child Psychol Psychiatry. 2001;42:963-70.

31. Carnell S, Wardle J. Measuring behavioural susceptibility to obesity: validation of the child eating behaviour questionnaire. Appetite. 2007;48:104-13.

32. Svensson V, Lundborg L, Cao Y, Nowicka P, Marcus C, Sobko T. Obesity related eating behaviour patterns in Swedish preschool children and association with age, gender, relative weight and parental weight--factorial validation of the Children's Eating Behaviour Questionnaire. Int J Behav Nutr Phys Act. 2011;8:134.

33. Ashcroft J, Semmler C, Carnell S, van Jaarsveld CH, Wardle J. Continuity and stability of eating behaviour traits in children. Eur J Clin Nutr. 2008;62:985-90.

34. Albuquerque G, Severo M, Oliveira A. Early life characteristics associated with appetite-related eating behaviors in 7-year-old children. J Pediatr. 2017;180:e2.

35. Durão C, Andreozzi V, Oliveira A, Moreira P, Guerra A, Barros $\mathrm{H}$, et al. Maternal child-feeding practices and dietary inadequacy of 4-year-old children. Appetite. 2015;92:15-23.
36. Stewart A, Marfell-Jones M, Olds T, de Ridder H. International Standards for Anthropometric Assessment. New Zeland: The International Society for the Advancement of Kinanthropometry; 2011.

37. de Onis M, Onyango AW, Borghi E, Siyam A, Nishida C, Siekmann J. Development of a WHO growth reference for schoolaged children and adolescents. Bull World Health Organ. 2007;85:660-7.

38. Real H, Oliveira A, Severo M, Moreira P, Lopes C. Combination and adaptation of two tools to assess parental feeding practices in pre-school children. Eat Behav. 2014;15:383-7.

39. Swinburn B, Sacks G, Ravussin E. Increased food energy supply is more than sufficient to explain the US epidemic of obesity. Am J Clin Nutr. 2009;90:1453-6.

40. Powell F, Farrow C, Meyer C, Haycraft E. The importance of mealtime structure for reducing child food fussiness. Matern Child Nutr. 2017;13.

41. Jacobi C, Schmitz G, Agras WS. Is picky eating an eating disorder? Int J Eat Disord. 2008;41:626-34.

42. Sleddens E, Kremers S, Thijs C. The Children's Eating Behaviour Questionnaire: factorial validity and association with Body Mass Index in Dutch children aged 6-7. Int J Behav Nutr Phys Act. 2008;5:49.

43. Rietmeijer-Mentink M, Paulis WD, van Middelkoop M, Bindels PJ, van der Wouden JC. Difference between parental perception and actual weight status of children: a systematic review. Matern Child Nutr. 2013;9:3-22.

44. Brown CL, Pesch MH, Perrin EM, Appugliese DP, Miller AL, Rosenblum K, et al. Maternal concern for child undereating. Acad Pediatr. 2016;16:777-82.

45. Guevara-Cruz M, Serralde-Zuniga AE, Frigolet Vazquez-Vela ME, Blancas Galicia L, Islas-Ortega L. Association between maternal perceptions and actual nutritional status for children in a study group in Mexico. Nutr Hosp. 2012;27:209-12.

46. Moore LC, Harris CV, Bradlyn AS. Exploring the relationship between parental concern and the management of childhood obesity. Matern Child Health J. 2012;16:902-8.

47. Warschburger P, Kroller K. "Childhood overweight and obesity: maternal perceptions of the time for engaging in child weight management". BMC Public Health. 2012;12:295.

48. Gerards SM, Gubbels JS, Dagnelie PC, Kremers SP, Stafleu A, de Vries NK, et al. Parental perception of child's weight status and subsequent BMI $\mathrm{z}$ change: the KOALA birth cohort study. BMC Public Health. 2014;14:291.

49. Bjelland M, Brantsaeter AL, Haugen M, Meltzer HM, Nystad W, Andersen LF. Changes and tracking of fruit, vegetables and sugarsweetened beverages intake from 18 months to 7 years in the Norwegian Mother and Child Cohort Study. BMC Public Health. 2013;13:793.

50. Northstone K, Emmett PM. Are dietary patterns stable throughout early and mid-childhood? A birth cohort study. Br J Nutr. 2008;100:1069-76.

51. Biro FM, Wien M. Childhood obesity and adult morbidities. Am J Nutr. 2010;91:1499s-505s.

52. Cornette R. The emotional impact of obesity on children. World Evid Based Nurs. 2008;5:136-41. 